\title{
24 Imagining Acupuncture: Images and the Early Westernisation of Asian Medical Expertise
}

\author{
Roberta Bivins
}

Chinese medicine draws upon a rich iconographic tradition; through this tradition (as well as careful observation, and the translation of medical texts), European medical practitioners and patients first became aware of the medical expertise of Asia. As a therapeutic modality defined by and practised in conjunction with a unique set of body maps, acupuncture's Western history in particular can be traced in the images through which it was represented. From Wilhelm Ten Rhijne's 1683 Mantissa Schematica:De Acupunctura to contemporary medical textbooks, changes in the European visual culture of acupuncture record different attempts to incorporate the technique into Western theory and practice - and expose, too, areas of cultural, medical, and scientific intransigence. Thus such images offer us primary evidence of the processes by which Chinese medical knowledge and culture has been globalised: how it has been perceived, translated, transmitted, received, and practised in other medical settings and cultures.

What we summarise under the heading of 'transmission' is, of course, a complex and multi-faceted process even within a single culture. As the 17 th-century French, natural philosopher Blaise Pascal recognised, the communication of knowledge involves many interactive elements (parsed by scholars of his work as content, medium, receiver and context). Perhaps more crucially, Pascal noted that successful communication depended not just on the value or truthfulness of the knowledge to be conveyed, but on knowing the tastes, pleasures and accepted truths of its would-be recipient:

We must pay attention to the person whom we are addressing: we must know their mind and heart, what principles they grant, what things they like... the art of persuasion consists in pleasing as much as in convincing - humans being, as they are, governed so much more by whim than by reason. ${ }^{1}$

Rather more recently, Elisabeth Hsu (among others) has explored the complex processes whereby Chinese medical knowledge is transmitted from one generation to another within China. The pathways Hsu isolated - 'secret', 'person-

1 For the intracultural transmission of (expert, scientific) knowledge, see the essays in Kusukawa and Maclean (eds) 2006, which also examine the role of images in stabilising polysemic knowledge. For Pascal, see specifically Scholar 2006, p. 3, where this quotation from Blaise Pascal, De l'Esprit Géométrique, c. 1655 , can be found. al' and 'standardised' - operate to a greater or lesser extent in any medical culture. ${ }^{2}$ One or another of these pathways may dominate the transmission process for any particular kind of medical knowledge, but will rarely if ever operate exclusively. For example, while medical education in the West may well be dominated by 'standardised' knowledge transmission, both 'personal' and 'secret' pathways certainly still operate, as illustrated by Julie Anderson and John Pickstone's work on the Charnely artificial hip, and by the persistence of the culture of surgical 'firms'. ${ }^{3}$

As Volker Scheid has demonstrated in relation to contemporary Chinese medicine, the specific content to be transmitted also affects the process and pace of transmission. ${ }^{4}$ In the sphere of medicine, three broad genres of knowledge are involved. Medical theory, comprising cosmologies, models of the body, and aetiologies of health and illness, is perhaps most readily transmissible across physical barriers, as it can take an exclusively textual form. ${ }^{5}$ But cultural barriers are another matter. Medical systems, as many scholars have argued, are highly culturally specific - and the availability of another culture's medical texts is no guarantee of their assimilability or persuasiveness. Medical practice, meanwhile, entails methods of diagnosis, prognosis and treatment; the content and style of the doctor-patient encounter; and the management of illness and health; these are perhaps best transmitted through personal contact and direct experience. And the technologies of medicine - its materia medica, instruments, devices, body maps, diagnostic charts, etc. - may be more or less transportable, but are rarely complete without both textual and experiential glosses. Consider, for example, the stethoscope - or more properly, the use of mediate auscultation (the technique of diagnosing chest conditions through listening indirectly to the sounds of respiration,

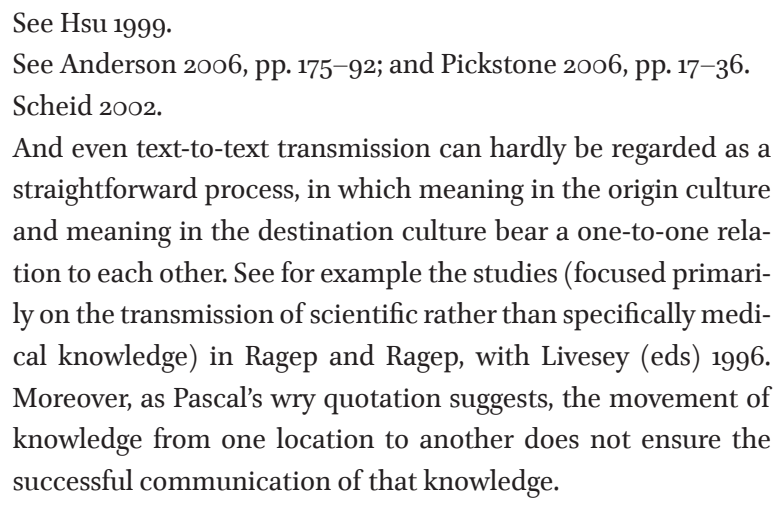
straightforward process, in which meaning in the origin culture and meaning in the destination culture bear a one-to-one relation to each other. See for example the studies (focused primarily on the transmission of scientific rather than specifically medical knowledge) in Ragep and Ragep, with Livesey (eds) 1996. Moreover, as Pascal's wry quotation suggests, the movement of knowledge from one location to another does not ensure the successful communication of that knowledge. 
etc.). Three components had to be transmitted for the practice to be successful and stable: the tool itself, the method of using it effectively, and the knowledge required to differentiate between newly audible sounds, and to associate those sounds with specific pathologies. Detailed knowledge of anatomy and personal experience using the technique under the close supervision of an expert proponent - in this case, the stethoscope's inventor, René Laënnec - were vital to its successful adoption, as were accessible and excellent translations of relevant treatises. ${ }^{6}$ Images too played a role in the eventual adoption of the stethoscope. In his first treatise on mediate auscultation, Laënnec presented detailed images and a cross-section of his novel (but fairly simple) instrument. These images allowed doctors remote from Paris to experiment with the tool themselves, and to test and assert its utility through direct experience. ${ }^{7}$

\section{Images and Acts of Transmission}

The study of images is increasingly recognised as essential to understanding the processes whereby expertise diffuses within, or passes from one culture to another. ${ }^{8}$ As the case of stethoscopy demonstrated, images can connect audiences and contexts otherwise separated by time, space, language or intellectual bent. Even within a single expert culture, images can operate as more than just illustrations: the philosopher Michael Ruse has offered compelling evidence that pictures - in particular, the portrayal of genetic processes in terms of a topographical landscape - were crucial to the communication of mathematical models of evolutionary genetics to mathematically disinclined evolutionary biologists, who only then could use them to produce key experiments. ${ }^{9}$ The use of images can also extend scarce resources and offer up surrogate experiences, as in the case of anatomical dissection and anatomical atlases. ${ }^{10}$ But images do not always play such straightforward roles, and certainly do not reliably speed the transmission process. Crucially, images can create unintended meanings; William Hunter, the famous 18th-century anatomist,

6 See Reiser 1978, and in more detail, Smith 1998. For a slightly different perspective, see Nicholson, 1993. On the importance of textual glosses for tools and images, see also Kusukawa and Maclean (eds) 2006.

$7 \quad$ See Smith 1998, pp. 183-216.

8 See for examples Gilman 1995, ch. 1; Kemp 1993, pp. 85-121. For more on the 'visual turn' in history, see Jordanova 2012.

Ruse 1996, pp. 303-10.

10 See Kemp 1996, esp. pp. 43-59; and Kemp, 1993; see also Berkowitz, 2011, pp. 259-62. noted that, while art could present information 'so plain that the unlearned as well as the learned understand it at first sight', it could also be dangerously misrepresentative. ${ }^{11}$

An additional complexity in the iconography of Western medicine and science since the Renaissance is that the images were intentionally directive as well as descriptive: they showed surgeons and artists 'routes' around and through the body, suggested 'appropriate' comparisons and valuations for the observed structures, and so constrained as well as communicated knowledge of the body's inner spaces. ${ }^{12}$ Mark Jenner's recent assessment of English physician Sir John Floyer's early 18th-century response to Chinese haptic diagnostics illustrates the operation of such constraints, even in Floyer's very positive response to the images of Chinese 'pulse-taking' in Andreas Cleyer's Specimen medicinae Sinicae. ${ }^{13}$ Moreover, images were routinely separated from the texts that glossed them, and re-used, derailing the intended transmission process and sometimes replacing their original meanings with entirely new ones..$^{14}$ As we will see, this has been common in cross-cultural transmission.

\section{Portraying Technique, Mapping Transmission?}

The case of acupuncture neatly exemplifies the difficulties of transmission and their effect on the globalisation of Chinese (or indeed any other) medical culture. Here, I will focus primarily on images created or copied by Westerners, and particularly medical professionals, whether intended for lay or medical audiences. Many of those images, particularly in the first modern wave of acupuncture's transmission to the West (roughly 1670 os to 173os), consisted of maps of the jingluo 經絡 and xue 穴 - the dense network of channels through which energy flows around the body and the specific points at which particular channels and flows could be stimulated by surface interventions, including the insertion of needles or the burning of moxa. Standing between the poles of text and technology, the original maps, charts and models of a subtle body were certainly tools in Chinese and Japanese medical practice and education. Foreign observers noted these uses. In Japan, interested (if faintly disapproving) Europeans also

\footnotetext{
11 Quoted in Kemp, 1993, p. 87. For unintended meanings, see also Luthy 2006.

12 Kemp 1993, p. 94 and Berkowitz 2011 hint at this, as do many primary source accounts. See Schiebinger 1989 for a detailed study of anatomical images and gender in science and medicine.

13 Jenner 2010, pp. 663-7.

14 Kusukawa and Maclean (eds) 2oo6, pp. 92-6.
} 
described the use of these medical images by an enthusiastically self-medicating laity to self-puncture - as one Dutch physician-observer put it, 'the needles are among the portable treasures of the capsule-loving nation'.15 This apparent transparency and directness in medical practice was much admired by Westerners more accustomed to the rhetoric and obscurantism - the 'verbal globs of honey' and 'contrived and controversial nonsense'- of elite European physick. ${ }^{16}$ And so they intended to emulate it in transmitting knowledge about acupuncture. One early proponent of the technique remarked: '

Since this method is so very different from the practice of Westerners, and since a thorough demonstration of it would involve a huge amount of labour and since this would not be suited to the flat surface of a book page, I thought it best to present illustrations clarifying separate dissertations. ${ }^{17}$

This physician clearly expected his maps to be attractive and useful to his intended Western audience: European medical professionals. His charts were to be virtual demonstrations, as well as maps for needle placement. He had, after all, seen similar documents working in exactly that way in Japan, as tools and guides of users' hands. But the maps and models also embodied an entirely different medical cosmology, and were imbued with considerable sophisticated medical theory. It was precisely these elements of the images that were obscured or erased when the role of images in Chinese and Japanese medical practice was unquestioningly equated with the purely illustrative and corroborative role that images were coming to have (at least in theory) in Western medicine.

Thus although often presented by their authors as direct copies of Asian originals, the maps that were actually transmitted to early modern Europe were in fact translations, and as such, were subject to exactly the same kind of errors that have plagued translations of Asian medical texts. Like Chinese medical terminology, the images were variously exoticised, domesticated, over-simplified, and embellished. Moreover, in seeking to understand the process of transmission, it is essential to remember that none of these images existed in a vacuum: they were 'read' in conjunction with an array of material and especially textual sources. Just as the images inflected (and reflected) Western perceptions of acupuncture, so responses to them were enduringly influenced by Western perceptions of China; similarly, internal debates and trends in Western

\footnotetext{
15 Engelbert Kaempfer, 'Acupuncture, A Japanese Cure for Colic', tr. in Bowers and Carrubba 1970, p. 304.

16 Ten Rhijne, 'De Acupunctura' and 'Mantissa Schematica', tr.in Carrubba and Bowers 1974, p. 375.

$17 \quad$ Tr. in Carrubba and Bowers 1974, p. 376.
}

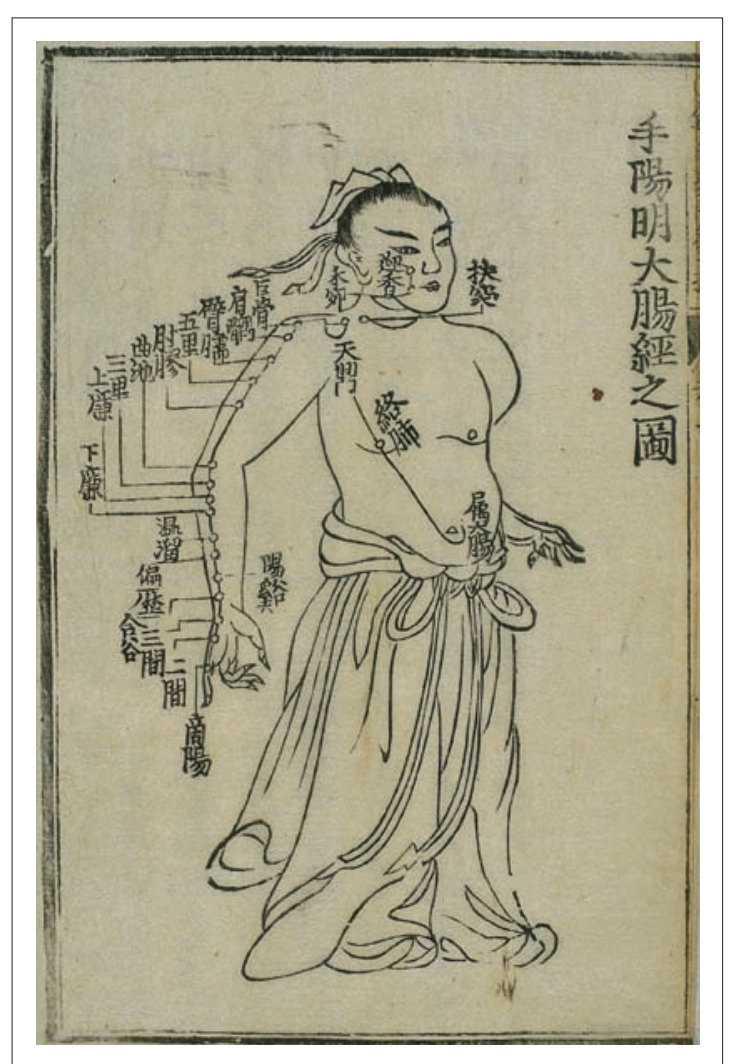

Figure 24.1 The Large Intestine Channel of Hand Yangming, from Gao Wu (Ming period, 1368-1644), Zhenjiu jiuying fahui (Explanations of 'Collected Gems of Acupuncture and Moxibustion), engraved and published in Japan. Library of Zhongguo zhongyi yanjiu yuan (China Academy of Traditional Chinese Medicine). (c) Wellcome Library, London, Loo37831

medicine played a profound role in both the iconography of acupuncture, and its reception. ${ }^{18}$

The earliest European medical treatise on acupuncture, Wilhelm Ten Rhijne's 1683 Dissertatio de Arthritide: Mantissa Schematica:De Acupunctura:Et Orationes Tres..., was based on Ten Rhijne's own observations of medical practice in Japan and his interpretations of rather painfully translated Chinese medical texts. Ten Rhijne confided to his readers:

I gathered and translated these into Latin, with the assistance of Iwanaga Zoko, a Japanese physician who knows Chinese, and with the assistance of Monttongi Sodaio, our interpreter, who speaks faltering Dutch in half words and fragmentary expressions. ${ }^{19}$

Indeed, Ten Rhijne grumbled, his interpreters' 'inexperience and limited vocabulary in Dutch' forced him to 'omit

For examples of interactions between internal medical debates and responses to acupuncture in the 18th and 19th centuries, see Bivins 2000, esp. chs 2 and 3.

19 Tr. in Carrubba and Bowers 1974, pp. 377-8. 


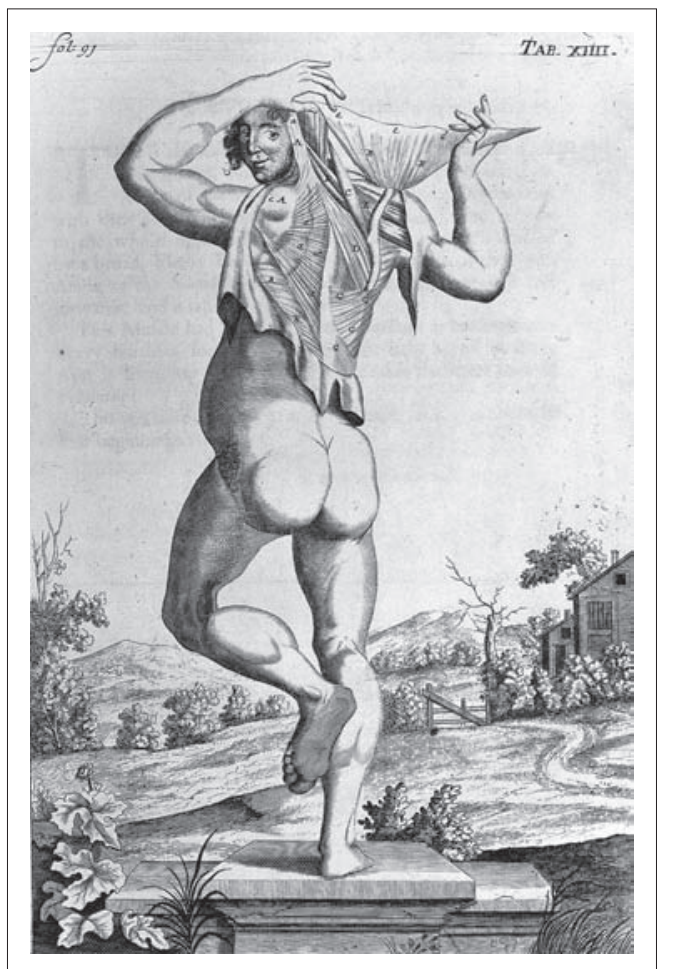

Figure 24.2 Anatomy of the upper back, from John Browne, A Compleat Treatise of the Muscles: as they appear in humane body, and arise in dissection..., London 1681. Note the similarities with Ten Rhijne's 'Chinese' image below, Fig. 5. (C) Wellcome Library, London, Loo28419

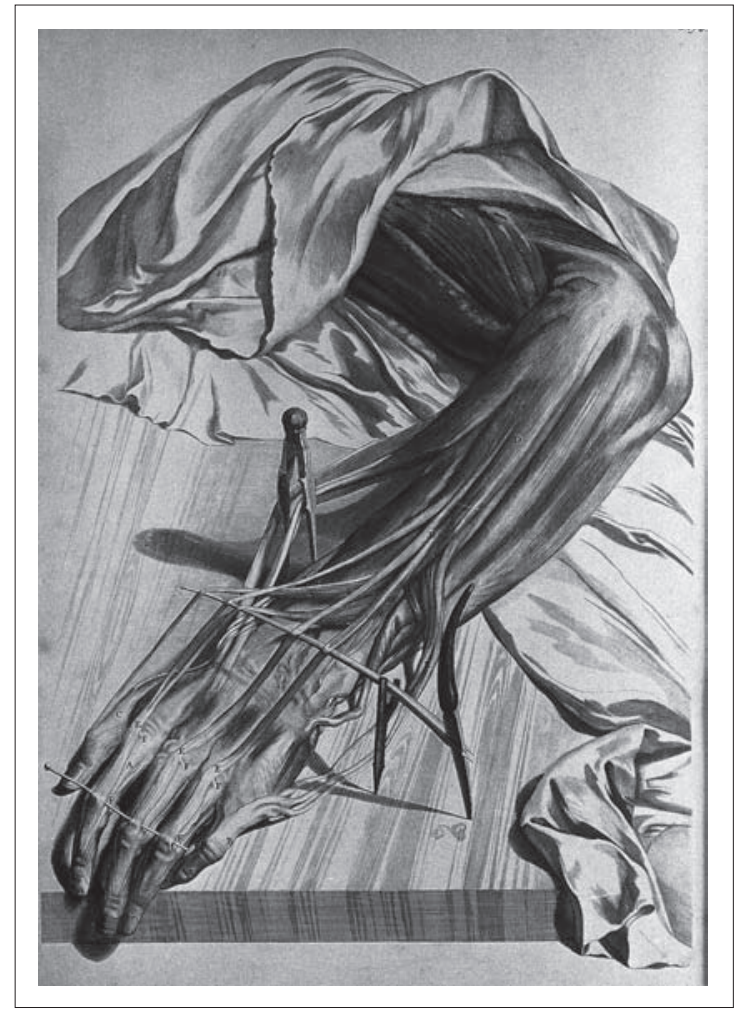

Figure 24.3 Dissected hand and arm, from Govard Bidloo, Anatomia Humani Corporis: centum \& quinque tabulis, engraved G. de Lairesse, Amsterdam 1685. () Wellcome Library, London, Looo6365

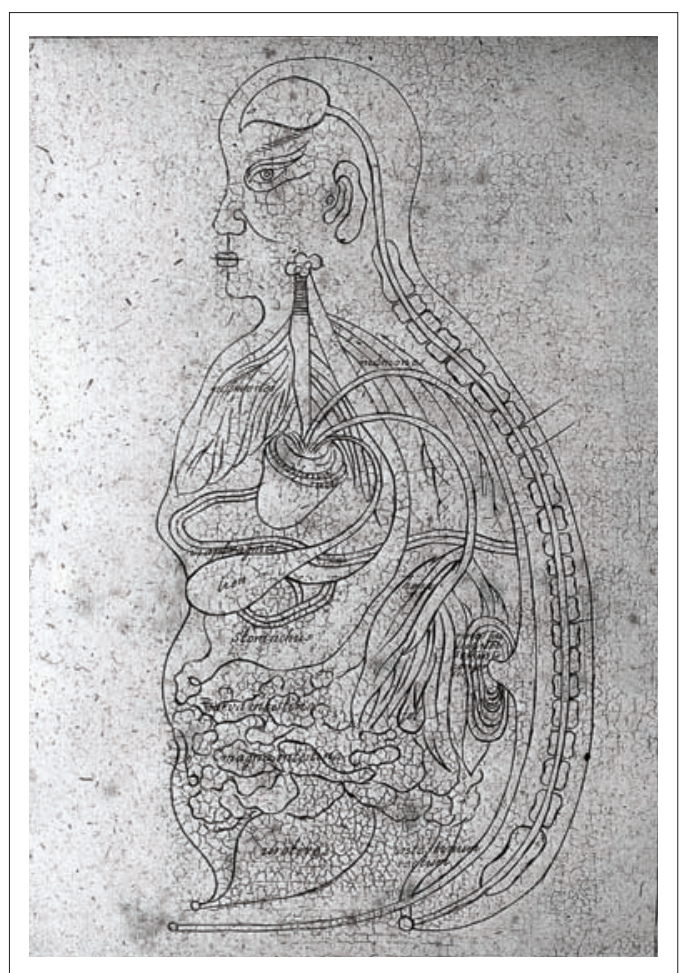

Figure 24.4 'Anatomical Figure’ from Andreas Cleyer, Specimen Medicinae Sinicae, sive opuscula medica ad mentem Sinensium, Frankfurt, 1682. (c) Wellcome Library, London, Looo4105

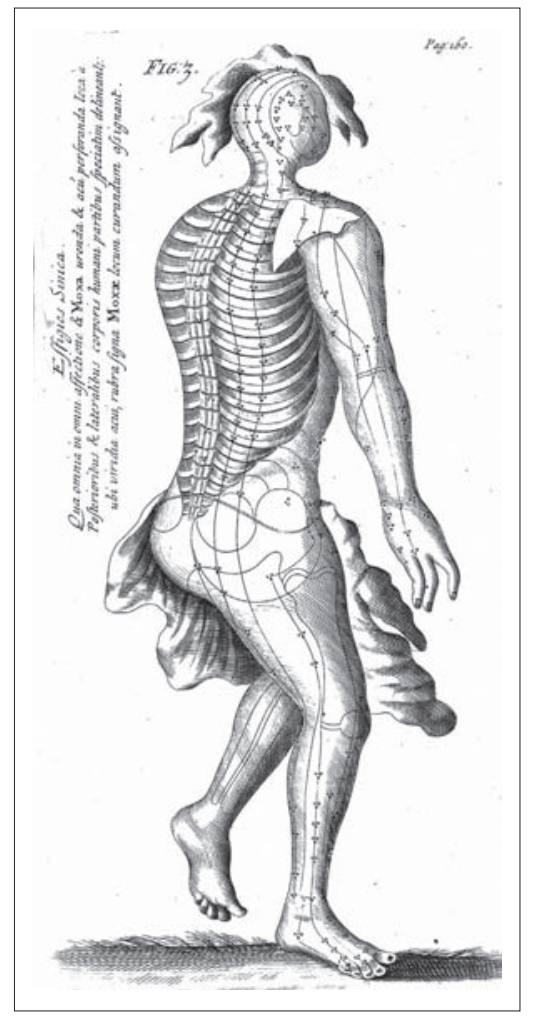

Figure 24.5 'Effigies Sinica' from Willem Ten Rhijne, Dissertatio de Arthritide: mantissa schematica: de acupunctura, London 1683. Compare John Browne's partially dissected Fig. 2. (c) Wellcome Library, London, Loo22387 
much that was written in Chinese in the original documents'. ${ }^{20}$ Just as Ten Rhijne's source texts were, in general, first translated from Chinese into Japanese, from Japanese into Dutch, and finally from Dutch into medical Latin, so too were his images multiply 'translated' - from Chinese originals to Japanese copies (see Fig. 1) and finally to images modified to suit European iconographic conventions.

In medical publishing, those conventions were rooted in rapidly changing models of the human body drawn from contemporary anatomical studies (see Figs 2, 3). Clearly, there is a striking contrast between the Asian and European styles of representing the body. From a Western perspective, the Chinese image shows a body mapped and by implication, known - primarily on the surface, and with little anatomical detail or specificity. Contemporary Chinese images of the internal organs did little to improve Western medical opinion, since they flatly contradicted the anatomical knowledge of the day. Indeed, as an example of the role of selection in the transmission pathway, it is worth noting that Ten Rhijne - medically trained and exhorting emulation, or at least experimentation in a medical audience - did not duplicate these images; his non-medical contemporary, the missionary Andreas Cleyer, did (see Fig. 4 ). By contrast, Western images from the same period as the Mantissa Schematica portrayed ever-greater levels of fine detail, and ever-deeper explorations beneath the body's surface. ${ }^{21}$ As a part of the pursuit of naturalism and the culture of 'virtual witnessing', a natomical art conventionally displayed the sheets of flesh which dissection peeled away. ${ }^{22}$ This convention is respected in the adaptations of Chinese body maps published with Ten Rhijne's account of acupuncture (Fig. 5), where similar flaps have been added. Additionally, the pose of one of Ten Rhijne's 'Chinese' figures shares many features with a Western anatomical image published in London only two years earlier (Fig. 2). Ten Rhijne himself would have been familiar with an earlier version of this same figure, which appeared in an anatomical treatise he presented to the Japanese official charged with controlling foreign trade in $1765 .^{23}$

Although rendered visually more familiar to European eyes by the addition of 'dissected' flaps of skin, Ten Rhijne's versions preserved the most distinctive aspect of acupuncture maps: the jingluo. Ten Rhijne also discussed them in his text. He acknowledged, 'a person especially skillful in

\footnotetext{
20 Ibid.

21 On 'surfacing the body interior', see Taylor 2005, pp. 746-8.

22 The classic discussion of 'virtual witnessing' is Shapin and Shaffer 1985; for more on anatomical art in the West, see Carlino 1999 .

23 Cook 2004, pp. 25-6.
}

the art of anatomy will belittle the lines and the precise points of insertion'. ${ }^{24}$ He knew that a Western audience used to the increasingly sophisticated heuristics of contemporary anatomical atlases might have other criticisms as well, that they would

censure the awkward presentation of the short notes on the diagrams, when these should be more closely identified with the walls of the blood vessels....$^{25}$

Nonetheless, he told his readers,

[t]he various movements of the blood must be learned through the precepts and rules as laid down by the Chinese... if the cure is to be undertaken according to their regimen. ${ }^{26}$

In other words, he asserted that theory and practice were inseparable. Ten Rhijne's successor, Kaempfer, would disagree, erasing the jingluo - fundamental to any understanding of acupuncture's modus operandi-from his own visual and textual accounts of the technique.

Engelbert Kaempfer, like Ten Rhijne, served as medical officer to the Dutch community on Deshima. Also like his predecessor, he was a close observer, deeply interested in the medicine of Japan. He was considerably less sympathetic, however, to its different model of the body. Where Ten Rhijne urged his European counterparts to experiment with acupuncture as it was used in China and Japan - as a compound entity combining practice and theory via needles, maps, and body-model - Kaempfer divorced the former element from the latter. Discussing both moxibustion and acupuncture, Kaempfer described in minute detail the exact methods practised in relation to burning, needle-insertion and movement. He stressed the care taken in choosing the location of insertion or the placement of moxa, but he dismissed the jingluo altogether: they were not anatomical and therefore not 'reasonable'.

The Main art lies in the knowledge of the parts which it is proper to burn [or puncture] in particular distempers. ... [O]ne would reasonably imagine that place to be the most proper which is nearest to the affected part, yet the operators frequently choose such others, as are not only very remote from it, but would be found, upon an Anatomical inquiry, to have scarce any communication with it, no more than by the common integuments. ... the most skillful Anatomist would be at a loss to find out any particular correspondence of these remote and differing parts with one another. ${ }^{27}$

In an earlier version of his account, Kaempfer added a further comment on his Japanese counterparts:

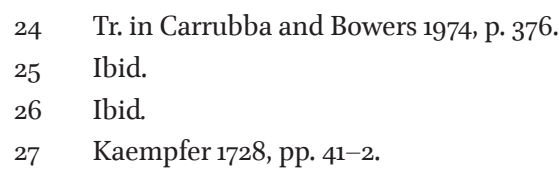




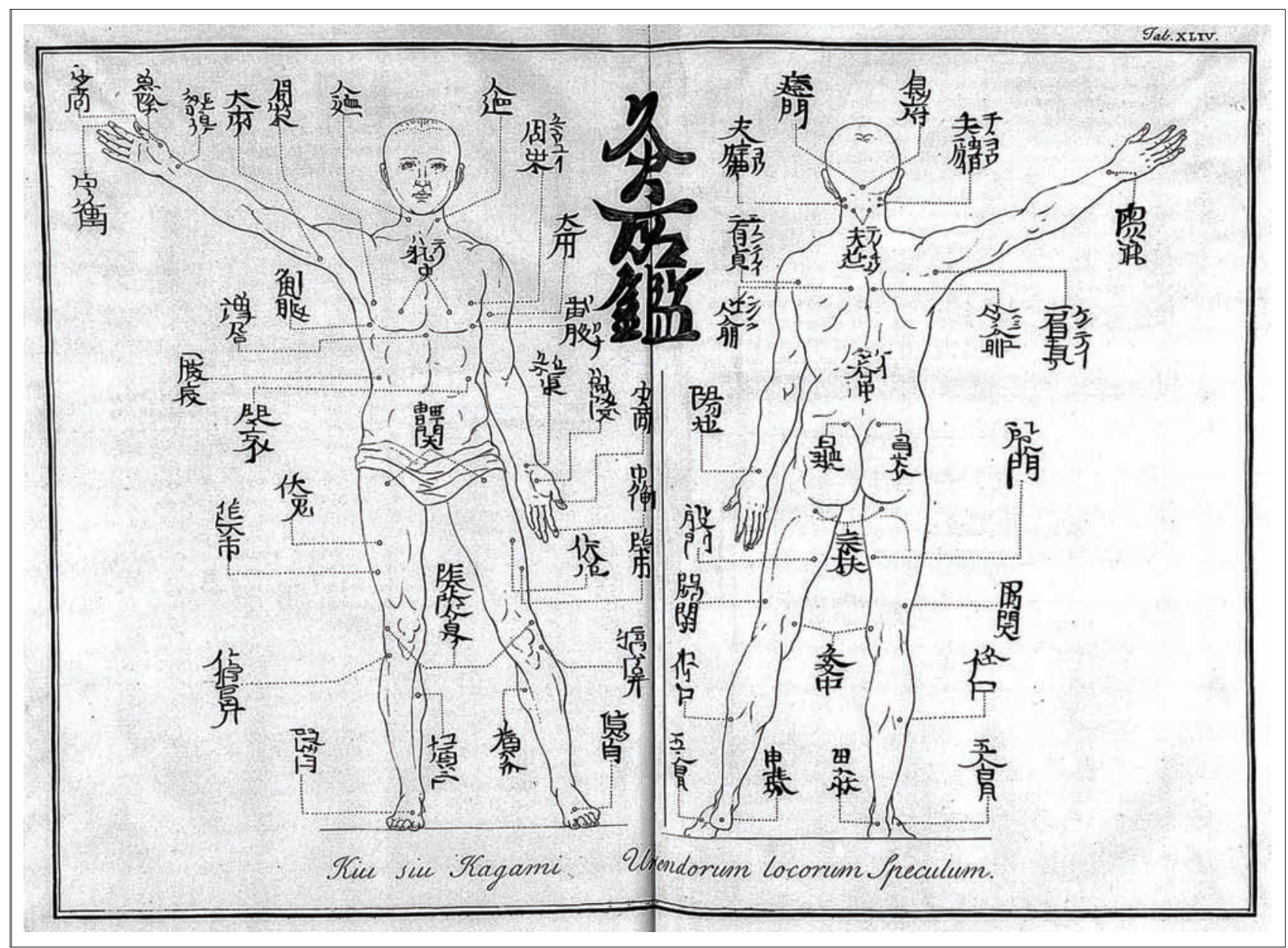

Figure 24.6 'Kiu siu Kagami Urendorum locorum Speculum' from Engelbert Kaempfer, The History ofJapan, London 1728. Note the absence of jingluo. (c) Wellcome Library, London, Loo23384

The results do not allow us to accuse them all of deception, yet sound reasoning does not permit us to testify in defence of all of them. ${ }^{28}$

The images Kaempfer included reflected and emphasised his materialist bias and scepticism of Chinese understandings of the body (see Fig. 6). ${ }^{29}$ They carefully charted the points, the empirical efficacy of which Kaempfer had witnessed. But they erased the structures underpinning them as anatomically disproven. With these images, the theoretical rationale of acupuncture's efficacy disappeared.

Images and texts addressing Chinese (and Japanese) medicine were examined by Western audiences over the course of the 18th and 19th centuries, though not always in conjunction with each other. The results, despite their authors' best efforts, were mixed. For some, the images served to confirm what (often exoticised) translations

\footnotetext{
28 Tr. in Bowers and Carrubba 1970, pp. 270-310.

29 For an expanded treatment of these two authors and texts, see Bivins 200o, ch. 2.
}

of Chinese medical texts had already suggested: that the medical skill of the East was negligible. English polemicist William Wotton, for example, wrote scathingly of Cleyer's illustrated translations:

The anatomical figures annexed to the tracts, which also were sent out of China, are so very whimsical, that a man would almost believe the whole to be a banter, if these theories were not agreeable to the occasional hints that may be found in the travels of the missionaries. ${ }^{30}$

While Wotton included a short extract of the translated text on the grounds that, 'few will in all probability have patience to go through them, since they are not very pleasant to read', he deleted the images altogether. ${ }^{31}$ On the other hand, almost a century later, Dujardin, in his compendious and influential Histoire de la Chirurgie reproduced Ten Rhijne's images exactly. ${ }^{32}$ Other scholars, including the French Encyclopédistes, mentioned the existence of

\footnotetext{
$30 \quad$ Wotton 1694, p. 152.

31 Ibid., p. 147.

$32 \quad$ Dujardin 1774, pp. $75^{-98}$.
} 
maps and figures depicting acupuncture or moxibustion points, sometimes referring to Ten Rhijne, Kaempfer, or Dujardin - but did not reproduce the images themselves. Images were expensive to reproduce, and these 'curious anatomies' were clearly not considered important enough to justify their additional cost.

Although maps of the body's surface were among the most dramatic and controversial Western representations of acupuncture, they did not provide the only images of the technique. The technology of acupuncture - needles, needle cases, striking implements - and, in the 19th century, three-dimensional figures too, were well-studied and frequently portrayed, particularly in medical texts and instrument catalogues. Even authors who ignored Ten Rhijne and Kaempfer's body-maps often included images of the implements of acupuncture. ${ }^{33}$ The drawback to their visual prevalence, and indeed the (again) orientalised beauty of many of these images, was that they tacitly reinforced Western perceptions of acupuncture as a standalone technology, to be applied purely empirically and in accordance with Western anatomical understandings of the body. Later, as in the 19th-century British study of the technique authored by James Morss Churchill, the deliberate Westernisation of therapeutic needling was reflected in a very Westernised representation of the needle itself. (Figs 7, 8). These images, however, were nonetheless important in widening access to the technique, much as they had been in the nearly contemporaneous case of the stethoscope. ${ }^{34}$ Doctors looking at Churchill's pictures could make their own acupuncture needles, and could test in person the miraculous, incomprehensible and therefore almost unbelievable efficacy of therapeutic needling in certain conditions.

The late 19th and 2oth centuries brought significant changes in the pathways by which Westerners, whether of the laity or the medical profession, accessed information about acupuncture. Immigration brought whole communities, with their medical practitioners and practices, to Western Europe and North America, where the latter swiftly gained a following among locals. ${ }^{35}$ In 1887 , for example, a US commentator noted: 'Many of the Chinese stores in our American cities keep a supply of Chinese drugs, and all of them sell Chinese proprietary medicines'. Alongside these over-the-counter remedies, such stores often hosted a Chinese practitioner able to diagnose and treat patients individually. ${ }^{36}$ New and more accurate translations of

33 See for example Heister 1743, p. 314.

34 See above, and Smith 1998.

35 Liu 1998; Marcus and Chen 2011.

36 Culin 1887. See also Liu, 1998; Shah 2001, pp. 55-6, 213 et passim.

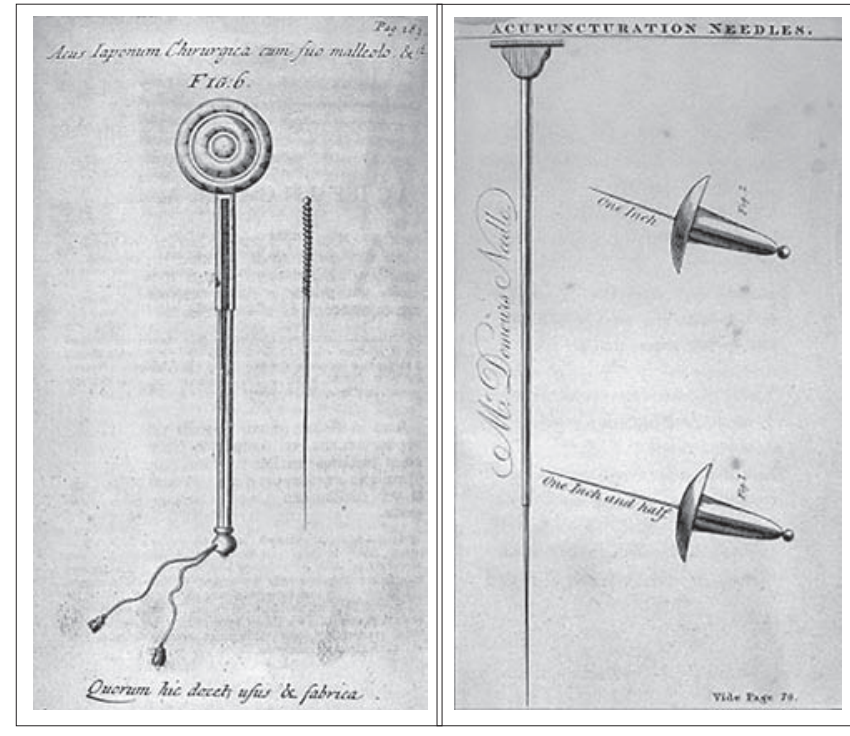

Figure 24.7 Acupuncture implements, as illustrated in Willem Ten Rhijne, Dissertatio de Arthritide: mantissa schematica: de acupunctura, London 1683

Figure 24.8 Mr Demours' Needles', from James M. Churchill, $A$ Treatise on Acu-puncturation; being a description of a surgical operation originally peculiar to the Japonese [sic] and Chinese, and by them denominated Zin-King, now introduced into European practice, with directions for its performance, and cases illustrating its success, London, 1821

Chinese medical, cosmological and philosophical texts likewise became more readily available, and Chinese language originals were mass-produced for the migrants; in Philadelphia, for example, complete copies of the Golden Mirror sold for $\$ 2.25$ in $1887 .{ }^{37}$ Chinese culture and its productions more generally became the subject of popular interest and enquiry, sometimes in ways that encouraged appreciation, rather than orientalism or racial stereotyping. ${ }^{38}$ And more Westerners were able to travel to East Asia to observe or study acupuncture in situ.

Nonetheless, even with these new avenues of transmission, images and models have remained central to understandings of acupuncture in the West. Like their predecessors, they reflect syntheses of different models of the body. Anatomical carcasses, stripped of skin but covered in $x u e$, dominate educational texts, while popular accounts and introductions - for example Ted Kaptchuck's Web That Has No Weaver - carries diagrams which could have been taken directly from Ten Rhijne's 'Japanese' images of three centuries before. Western commercial representations of acupuncture, meanwhile, heavily emphasise the exotic, the

37 For an interesting account of the creation of the Golden Mirror itself, and the ways in which this too was a process of selection, translation, and sometimes erasure, see Hanson 2003.

$38 \quad$ Zboray and Zboray 2004. 
unusual, and the historic qualities of 'Traditional Chinese Medicine' in images as well as text. ${ }^{39}$ Kaempfer's images remain popular. Their persistence may offer testimony to the accuracy with which he estimated Western tolerances for non-Western medical expertise - or to the ease with which its simpler lines, unlike those of Ten Rhijne's images, could be copied and reproduced. Visual distinctiveness here re-emphasises the now-attractive qualities of theoretical and practical divergence from a Western medical culture, which can be as mystifying, as obscure, and as alienating to its patients as Chinese medicine and culture once was to Western eyes.

So what, more broadly, do acupuncture's images, understood in their historical context, tell us about the processes by which medical knowledge and expertise become globalised? Clearly, whether philosophical, anthropological or historical, any model of transmission of expertise must include the following processes: the observation and collection of information, specimens, and technologies (and inevitably, therefore both accidental and deliberate selection); the translation, interpretation and description of the observed and collected materials; the publication and/or display of such materials in the destination culture; and the reception, re-interpretation, and response to them by the members of that culture. Both culture and chance inflect each stage of the process. A closed origin community, a higher market value for secret knowledge, cultural traditions about bodily privacy or sanctity, the mandates of governments, shipwreck, bookworm, sudden death, and of course, the personal tastes, ambitions and intellectual hobbyhorses of observers and observed: all can act as drivers of or as limits to comprehensive and persuasive cross-cultural transmission. Images cannot evade the exigencies of selection or of translation - nor can they escape culturally specific interpretation; indeed, as Western responses to Ten Rhijne and Kaempfer's images suggest, they may be particularly susceptible to interpretive drift and redefinition. Yet, as demonstrated by their persistence in the face of rapidly shifting technologies both of pedagogy and of diagnosis, images remain essential to the teaching and practice of medicine. Ten Rhijne himself acknowledged both the limitations and the value of imagery in communicating knowledge at a distance in another treatise, on leprosy in Asia:

It is not enough, for one who has never seen the disease, to send a description of it, consisting of a few hypotheses

39 For more on 2oth-century perceptions of acupuncture, see Bivins 2002, pp. 84-105; and on the use of tradition and exoticism in the commercial spread of Chinese (and Ayurvedic) medicine, see Bivins 2007, pp. 117-99. formed from guesswork rather than experience ... embellished, according to present day dash custom [sic], with much true-seeming chop-logic; making the nature and particularities of the disease like the paintings which have been made of it more from imagination than from real life. ${ }^{40}$

Such flawed and partial attempts, he acknowledged, had some merit: 'if everyone adds a line, then the picture will gradually become like nature, and after thorough observation, be at last completed'. They were, in short, better than nothing. Crucially, however, Ten Rhijne exhorted his readers not to 'stare at the manikin... always keep the living object in view'. Scholars, practitioners, and patients today continue to debate whether contemporary Western images (and imaginings) of acupuncture - biomedical, popular, or scholarly - are ossified, orientalised, or like nature', and with what experimental or experiential tools each additional line should be drawn. I have suggested here that such questions are of more than theoretical interest. Remarkable visual representations of acupuncture played a central role in acupuncture's early westward transmission and its initial reception in Europe. ${ }^{41}$ But with observers captivated or repelled by these 'manikins' and largely cut-off from the 'living object', acupuncture as it was originally understood, practised, and experienced (as an entity comprised of theories, practices, and technologies) was first transfigured, and then erased from view until the mid-2oth century.

\section{Bibliography}

\section{Primary Sources}

Kaempfer, E. 1728, The History ofJapan, London.

Dujardin, M.F. 1774, Histoire de la Chirurgie, depuis son origine jusqu'à nos jours, vol. 1, Paris: L'Imprimerie Royal.

Heister, L. 1743, A General System of Surgery in Three Parts, London: W. Innys.

Ten Rhijne, W. [1687] 1937, Treatise on the Asiatic Leprosy, Amsterdam: Abraham Van Someren, tr. D. Schoute, in Opuscula Selecta Neerlandicorum de Arte Medica, fasc. 14, Amsterdam: 'Sumptibus Societatis', 36-113.

Wotton, W.B.D. 1694, Reflections upon Ancient and Modern Learning, London: Peter Buck.

\section{Secondary Sources}

Anderson, J. 2006, 'Greenhouses and body suits: The challenge to knowledge in early hip-replacement surgery, 196o-1982', in Timmermann and Anderson (eds), $175^{-92 .}$

Baigrie, B. 1996, Picturing Knowledge: Historical and Philosophical Problems Concerning the Use of Art in Science, Toronto: University

40 Ten Rhijne 1687, pp. 37-40.

$41 \quad$ For a detailed account of this process, see Bivins 2000. 
of Toronto Press.

Berkowitz, C. 2011, 'The beauty of anatomy: visual displays and surgical education in early nineteenth-century London', Bulletin of the History of Medicine 85.2 (Summer), 248-78.

Bivins, R. 2000, Acupuncture, Expertise and Cross-cultural Medicine, Basingstoke: Palgrave.

2002, 'Acupuncture and innovation: 'New Age' medicine in the NHS', in Stanton (ed.), 84-105. 2007, Alternative Medicine? A History, Oxford: oup.

Bowers, J. and R. Carrubba 1970, 'The doctoral thesis of Engelbert Kaempfer: "On tropical diseases, oriental medicine and exotic natural phenomenon", Journal of the History of Medicine and Allied Sciences 25, 270-310.

Bynum, W.F. and R. Porter (eds) 1993, Medicine and the Five Senses, Cambridge: CUP, 134-53.

Carlino, A. 1999, Books of the Body: Anatomical Ritual and Renaissance Learning, Chicago: University of Chicago Press.

Carrubba, R. and J. Bowers 1974, 'The western world's first detailed treatise on acupuncture: Willem Ten Rhijne's "de Acupunctura”, Journal of the History of Medicine and Allied Sciences, 29, 371-98.

Cook, H. 2004, 'medical communication in the first global age:Willem ten Rhijne in Japan, 1674-1676', Academia Sinica 11, 16-36.

Culin, S. 1887, 'The Practice of medicine by the Chinese in America', reprinted from Medical and Surgical Reporter, 19 March, available online at http://babel.hathitrust.org/cgi/pt?id=uc2. ark\%3 A\%2F1396o\%2Ft22b8w48v;page=root;view=image;size=100;seq=6;num=2 (accessed 2/7/2013).

Gilman, S. 1995, Picturing Health and Illness: Images of Identity and Difference, Baltimore: Johns Hopkins University Press.

Hanson, M. 2003, 'The Golden Mirror in the imperial court of the Qianlong Emperor, 1739-1742', Early Science and Medicine 8.2, 111-47.

Hsu, E. 1999, The Transmission of Chinese Medicine, Cambridge: CuP.

Jenner, M. 2010, 'Tasting Lichfield, touching China: Sir John Floyer's senses', The Historical Journal 53: 647-70.

Jordanova, L. 2012, The Look of the Past: Visual and Material Evidence in Historical Practice, Cambridge: cup.

Kemp, M. 1993, “"The Mark of Truth”: Looking and learning in some anatomical illustrations from the Renaissance and eighteenth century', in Bynum and Porter (eds), 85-121.

1996, 'Temples of the body and temples of the cosmos: vision and visualisation in the vesalian and copernican revolutions', in Baigrie, $40-85$.

Kusukawa, S. and I. Maclean (eds) 2006, Transmitting Knowledge:
Words, Images and Instruments in Early Modern Europe, Oxford: OUP.

Liu Haiming 1998, 'The resilience of ethnic culture: Chinese herbalists in the American medical profession', Journal of Asian American Studies 1.2, 173-91.

Luthy, C. 2006, 'Where logical necessity becomes visual persuasion: Descartes' clear and distinct illustrations', in Transmitting Knowledge: Words, Images and Instruments in Early Modern Europe, Oxford: oup, 97-133.

Marcus, K. and Chen Yong 2011, 'Inside and outside Chinatown: Chinese elites in exclusion era California', Pacific Historical Review $80.3,369-400$.

Nicholson, M.1993, 'The introduction of percussion and stethoscopy to nineteenth century Edinburgh', in Bynum and Porter (eds), 134-53.

Pickstone, J. 2006, 'Bones in Lancashire: towards long-term contextual analysis of medical technology', in Timmermann and Anderson (eds), $17-36$.

Ragep, F.J. and S.P. Ragep, with S. Livesey (eds) 1996, Tradition, Transmission, Transformation: Proceedings of two conferences on pre-modern science, held at the University of Oklahoma, Leiden: Brill.

Reiser, S.J. 1978, Medicine and the Reign of Technology, Cambridge: CuP. Ruse, M.1996, 'Are pictures really necessary? The case of Sewall Wright's “Adaptive Landscapes"', in Baigrie, 303-38.

Scheid, V. 2002, Chinese Medicine in Contemporary China: Plurality and Synthesis, Durham, NC.: Duke University Press.

Schiebinger, L. 1989, The Mind Has No Sex: Women in the Origins of Modern Science, Cambridge MA: Harvard University Press.

Scholar, R. 2006, 'Introduction', in Kusukawa and Maclean (eds), 1-9. Shah, N. 2001, Contagious Divides: Epidemics and Race in San Francisco's Chinatown, Berkeley:University of California Press.

Shapin, S. and S. Shaffer 1985, Leviathan and the Air-Pump: Hobbes, Boyle, and the Experimental Life, Princeton: Princeton University Press.

Smith, H. 1998, 'The transmission of medical knowledge: the introduction and acceptance of mediate auscultation in Great Britain, 1816-1843', PHD diss., University of Minnesota.

Stanton, J. 2002 (ed.), Innovations in Health and Medicine, London: Routledge, $84-105$

Taylor, J. 2005, 'Surfacing the body interior', Annual Review of Anthropology 34, 741-56.

Timmermann, C. and J. Anderson (eds) 2006, Devices and Designs: Medical Technologies in Historical Perspective, Basingstoke: Palgrave.

Zboray, R. and M.S. Zboray 2004, 'Between "Crockery-dom and Barnum: Boston's Chinese Museum, 1845-47', American Quarterly $56.2,271-307$. 